\title{
EMERGÊNCIA E DESENVOLVIMENTO DE PLÂNTULAS DE CULTIVARES DE MARMELEIRO PARA USO COMO PORTA-ENXERTOS ${ }^{1}$
}

\author{
RAFAEL PIO $^{2}$, EDVANALVES CHAGAS ${ }^{3}$, WILSON BARBOSA ${ }^{4}$, GUILHERME SIGNORINI $^{5}$, ÂNGELOALBÉRICO ALVARENGA $^{6}$, \\ ENILSON ABRAHÃO ${ }^{7}$, JAIRO OSVALDO CAZETTA $^{8}$, FÁBIO ALBUQUERQUE ENTELMANN ${ }^{8}$
}

RESUMO - O presente trabalho teve como objetivo estudar a emergência e o desenvolvimento de plantas de marmeleiro, com potencial para serem utilizadas como porta-enxertos. O trabalho foi desenvolvido no Centro APTA Frutas/IAC, de maio/05 a janeiro/ 06. Sementes dos marmeleiros 'Mendoza INTA-37', 'Provence', 'Portugal' e 'Japonês' foram extraídas de frutos maduros, lavadas em água corrente, secas à sombra por $48 \mathrm{~h}$ e estratificadas a frio por 20 dias. Em seguida, foram semeadas em bandejas de poliestireno (72 células, capacidade de $120 \mathrm{~cm}^{3} /$ célula) contendo a vermiculita como substrato. Foi feito contagem da porcentagem de emergência após 30 dias da semeadura, a cada 10 dias, em um total de quatro coletas. Em seguida, foi retirada uma amostra de 10 plântulas por repetição e avaliados a altura média da parte aérea, $\mathrm{n}^{\mathrm{o}}$ de folhas, massa seca média da parte aérea e das raízes. Foram ainda separados 10 plântulas uniformes e representativos de cada repetição e transplantados para sacos plásticos (capacidade de 3 L) contendo como substrato solo + esterco de curral curtido + areia $(1: 1: 1 \mathrm{v} / \mathrm{v})$. As plântulas permaneceram em viveiro telado (sombrite $50 \%)$, sendo irrigadas periodicamente. A cada 30 dias, foram mensurados a altura e o diâmetro das plântulas até o final da sexta avaliação (após 180 dias do transplantio). Concluiu-se que o marmeleiro 'Japonês' apresenta maior porcentagem de emergência (70\%), altura das plântulas $(111,83 \mathrm{~cm})$ e diâmetro $(0,7 \mathrm{~cm})$, possuindo maior performance e uma excelente alternativa como porta-enxerto para marmeleiros.

Termos para indexação: Chaenomeles sinensis L., Cydonia oblonga Mill., propagação.

\section{EMERGENCY AND PLANT DEVELOPMENT OF QUINCE CULTIVARS TO BE USED AS ROOTSTOCK}

\begin{abstract}
The present work has as objective to study the emergency and development of quince seedlings with potential to be used as rootstock. The work was developed in the APTA Center Fruits/IAC, from May/05 to January/06. Seeds of 'Mendoza INTA37', 'Provence', 'Portugal' and 'Japonês' quince were collected from mature fruits, washed in water, dried under shade for $48 \mathrm{~h}$, and

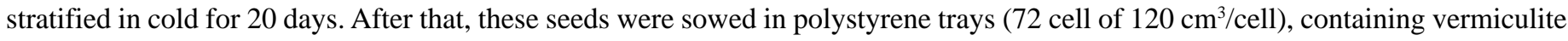
as substrate. The percentage of emergency was determined after 30 days, at intervals of 10 days, in a total of four collections. On the end of this period, 10 seedlings were removed from each replication and evaluated the height of the aerial part, the number of leaves, and the medium dry mass of aerial and root parts. Also, 10 uniform representative seedlings of each replication were separeted and transplanted to polyethylene bags (capacity of $3 \mathrm{~L}$ ) containing substrate composed by soil + cattle manure + sand (in the volumetric proportion of 1:1:1) fertilized with $191 \mathrm{~g} \mathrm{CaHPO}_{3}, 10 \mathrm{~g} \mathrm{KCl}_{\text {and }} 100 \mathrm{~g} \mathrm{CaCO}_{3}$ in $100 \mathrm{~L}$ substrate. Then plants were maintained under shading sieve (50\% shading), being irrigated periodically. The height and diameter of seedlings were evaluated at intervals of 30 days until the end of the sixth evaluation (after 180 days of transplanting). The 'Japonês' quince presented greater emergency percentage $(70 \%)$, shoot length $(111,83 \mathrm{~cm})$ and diameter $(0,7 \mathrm{~cm})$, showing it has greater performance and an excellent alternative as quince rootstocks.
\end{abstract}

Index terms: Chaenomeles sinensis L., Cydonia oblonga Mill., propagation.

\section{INTRODUÇÃO}

Dentre as frutas de clima temperado, o marmelo é, sem dúvida, uma das mais interessantes e apreciadas frutas em todo o mundo, principalmente pelo alto teor de pectina, larga aplicação na industrialização, para a fabricação de marmeladas, compotas e geléias. Introduzido no Brasil em 1532 por Martim Afonso de Souza, os marmelos e a marmelada foram os principais e os primeiros produtos de exportação paulista, antecessora ao café. No mundo antigo e no Brasil colonial, poucos frutos como o do marmeleiro tiveram tão relevante papel e, atualmente, é difícil encontrar uma frutífera com seu valor histórico-social tão pouco difundida e estudada. As causas prováveis desse pequeno interesse devem residir na utilização pouco nobre do marmelo, somente como matéria-prima industrial e no incipiente consumo ao natural (Pio et al., 2005a).

\footnotetext{
(Trabalho 132-2006). Recebido em : 29-08-2006. Aceito para publicação em 08-12-2006.

${ }^{2}$ Eng $^{\circ}$. Agrônomo, D.Sc., Professor Adjunto da Universidade Estadual do Oeste do Paraná (UNIOESTE). Rua Pernambuco, no 1777 , C.P. 1008, Centro, 85960-000, Marechal Cândido Rondon-PR. Autor para correspondência: rafaelpio@hotmail.com

${ }^{3}$ Eng. Agr., Dr., Pesquisador Científico Centro APTA Frutas/IAC, Jundiaí-SP. E-mail: echagas@iac.sp.gov.br

${ }^{4}$ Biólogo, M.Sc., Pesquisador Científico Centro Experimental Central/IAC, Campinas-SP. E-mail: wbarbosa@iac.sp.gov.br

${ }^{5}$ Acadêmico Agronomia, ESALQ/USP, estagiário Centro APTA Frutas/IAC-Bolsista I.C. FAPESP, Jundiaí-SP. E-mail: signorini1986@yahoo.com.br

${ }^{6}$ Eng. Agr., Dr., Pesquisador Científico CTSM/EPAMIG, Lavras-MG. E-mail: angelo@epamig.ufla.br enilson@epamig.ufla.br

${ }^{7}$ Eng. Agr., Dr., Prof. Departamento de Tecnologia, Universidade Estadual Paulista - FCAV/UNESP, Jaboticabal-SP. E-mail: cazetta@fcav.unesp.br

${ }^{8}$ Eng. Agr., Mestrando em Fitotecnia, ESALQ/USP-Bolsista FAPESP, Piracicaba-SP. E-mail: fabioburi@uol.com.br
} 
A Empresa de Pesquisa Agropecuária de Minas Gerais (EPAMIG) e o Instituto Agronômico (IAC), cientes da importância dessa cultura para a fruticultura nacional, notadamente para as pequenas propriedades rurais, onde a marmelocultura constitui uma excelente alternativa de alta rentabilidade, vêm desenvolvendo pesquisas com o objetivo de resolver os entraves ao seu desenvolvimento. Nesse sentido, alguns trabalhos de relevância foram priorizados na tentativa de revitalizar a marmelocultura nacional e, dentre esses, o de maior importância foi o estudo envolvendo o manejo fitotécnico do marmeleiro 'Japonês' (Chaenomeles sinensis L.), com potencial para servir de porta-enxerto para os demais marmeleiros explorados comercialmente (todos da espécie Cydonia oblonga Mill.) e até mesmo para pereiras e nespereiras (Abrahão et al., 1991).

No sentido de definir o protocolo de propagação para o marmeleiro 'Japonês', alguns trabalhos envolvendo a propagação vegetativa foram realizados, porém não foi obtido êxito no enraizamento de suas estacas (Pio et al., 2005b; 2004a; 2004b).

Quanto à propagação seminífera, constatou-se que o mesmo possui elevada germinação de suas sementes, boa afinidade com as principais cultivares-copa do gênero Cydonia e vem proporcionando boa performance no campo como portaenxerto (Abrahão et al., 1995; 1996). No entanto, há carência de informações no que tange à emergência das plântulas, desenvolvimento no viveiro e ainda ao tempo de crescimento do porta-enxerto até atingir o ponto da enxertia. Além do mais, seria interessante comparar essa cultivar de marmeleiro com os demais marmeleiros utilizados comercialmente no Brasil, principalmente na produção de porta-enxertos, para assim verificar as reais potencialidades do marmeleiro 'Japonês', uma vez que se trata de gênero diferente dos demais.

No caso específico do marmeleiro, tanto do gênero Chaenomeles quanto do Cydonia, não obstante a propalada fecundidade de seus frutos, desconhece-se o potencial relativo de formação de sementes viáveis e o desenvolvimento de pésfrancos obtidos por sementes das variedades mais comuns, disponíveis em nossas condições (Campo Dall'Orto, 1982).

Nesse contexto, o objetivo do presente trabalho foi estudar a emergência e o desenvolvimento de plantas de marmeleiros com potencial para serem utilizadas como portaenxertos.

\section{MATERIAL E MÉTODOS}

O presente trabalho foi desenvolvido no Centro APTA Frutas/IAC, no período de maio/05 a janeiro/06. Foram coletados frutos dos marmeleiros 'Mendoza INTA-37', 'Provence', 'Portugal' e 'Japonês', de plantas-matrizes de oito anos de idade, localizadas a campo, em abril de 2005, na Fazenda Experimental da EPAMIG, Maria da Fé-MG. As sementes foram extraídas e lavadas em água corrente, secas à sombra por 48 h e estratificadas em caixas de areia a frio (geladeira com temperatura em torno de $4^{\circ} \mathrm{C}$ ) por 20 dias. Em seguida, foram semeadas em bandejas de isopor (72 células, capacidade de $120 \mathrm{~cm}^{3} /$ célula) contendo a vermiculita como substrato.

Aos 30; 40; 50 e 60 dias após a semeadura, foi avaliada a porcentagem de emergência, adotando-se o delineamento inteiramente ao acaso, com quatro repetições e 72 sementes por parcela. Após a última avaliação da germinação (60 dias), retirouse uma amostra de 10 plantas por parcela para avaliação da altura da parte aérea, número de folhas, massa seca da parte aérea e das raízes.

Foram escolhidas 10 plantas uniformes e representativas de cada parcela, transplantadas para sacos plásticos pretos $(18 \mathrm{x}$ $30 \mathrm{~cm}$, capacidade de $3 \mathrm{~L}$ ) contendo como substrato a mistura composta por solo + esterco de curral curtido + areia (1:1:1 v/v), enriquecido com $191 \mathrm{~g}$ de superfosfato simples, $10 \mathrm{~g}$ de cloreto de potássio e $100 \mathrm{~g}$ de calcário para cada $100 \mathrm{~L}$ de substrato. $\mathrm{O}$ segundo experimento foi conduzido no delineamento inteiramente casualizado, com quatro repetições de 10 plantas por parcela. As plantas permaneceram em viveiro telado (50\% de sombreamento), irrigadas periodicamente. A cada 30 dias, foi avaliada a altura e o diâmetro das plantas (no ponto de enxertia, $15 \mathrm{~cm}$ acima do coleto), até se completarem 180 dias do transplantio.

Os dados foram submetidos à análise de variância, pelo teste $\mathrm{F}$, e as médias foram comparadas pelo teste Tukey, ao nível de 5\% de probabilidade, de acordo com as indicações de Gomes (2000), utilizando-se do Sistema para Análise de Variância - SISVAR (Ferreira, 2000).

\section{RESULTADOS E DISCUSSÃO}

Na primeira avaliação das plântulas, observou-se superioridade do marmeleiro 'Japonês' frente aos demais marmeleiros, o qual apresentou 54,75\% de emergência, índice de germinação cerca de quatro vezes a mais que os demais, que não diferiram entre si. Na segunda avaliação, houve acréscimo de aproximadamente $10 \%$ para o 'Japonês' e aumento pouco significativo para os demais; a partir da terceira avaliação, ocorreu maior diferença entre os marmeleiros, com grande destaque do marmeleiro 'Japonês' frente aos demais, atingindo $70 \%$ de plântulas emergidas, o que corresponde a um índice aproximadamente 50\% maior que os demais (Tabela 1). Vale frisar que as sementes do marmelo 'Japonês' mantiveram alta porcentagem de germinação e de emergência em níveis aceitáveis, mostrando similaridade com as de pêra (Barbosa et al., 1997), também usadas como porta-enxerto na produção de mudas de marmeleiro.

Campo Dall'Orto (1982) relatou elevada perda de plântulas de marmeleiro do gênero Cydonia na fase de emergência devido à elevada ocorrência de damping-off, o que não foi observado para a cultivar Japonês, mas foi notado nos demais genótipos estudados no presente trabalho. Possivelmente, seja essa uma das causas da superioridade do 'Japonês'. Campo Dall'Orto et al. (1987) constataram, ainda, que o marmeleiro 'Portugal' apresentou apenas $26 \%$ de emergência, em condições parecidas com o do presente trabalho. Assim, esse é mais um indício do vigor do marmeleiro 'Japonês', conforme descrito por Abrahão et al. (1992).

Quanto à avaliação das plantas após o transplantio, os marmeleiros 'Mendoza INTA-37' e 'Provence' apresentaram maior altura da parte aérea e, conseqüentemente, maior número de folhas. Quanto à massa seca da parte aérea, 'Mendoza INTA-37'

Rev. Bras. Frutic., Jaboticabal - SP, v. 29, n. 1, p. 133-136, Abril 2007 
novamente se destacou entre os demais $(115,75 \mathrm{mg})$, seguido dos marmeleiros 'Japonês' e 'Provence' ( $87 \mathrm{mg}$ e 84,75 mg). No que se refere à massa seca da raiz, os marmeleiros 'Mendoza INTA-37' e 'Japonês' apresentaram os maiores valores (18,5 mg e $15 \mathrm{mg}$ ) (Tabela 2).

Analisando o comportamento dos resultados da altura das plantas aos 30 dias após o transplantio, constatou-se que o marmeleiro 'Japonês' apresentou apenas uma pequena tendência de possuir maior vigor; mas destacou-se de forma cada vez mais acentuada dos demais nas avaliações subseqüentes, que não diferiram entre si (Tabela 3). Na avaliação feita aos 180 dias após o transplantio, as plântulas do marmeleiro 'Japonês' apresentaram $111,83 \mathrm{~cm}$ de altura, cerca de $60 \%$ a mais que as demais cultivares. Para o diâmetro do caule, apenas não houve diferença na primeira avaliação, mas, nas demais, o marmeleiro 'Japonês' novamente se destacou, chegando aos 180 dias do transplantio com $0,70 \mathrm{~cm}$ de diâmetro e uma diferença de aproximadamente $0,20 \mathrm{~cm}$ a mais que os outros genótipos em estudo (Tabela 4).

Levando em consideração o tempo gasto desde a extração da semente até as mudas de marmeleiro 'Japonês atingirem o ponto de enxertia, foram demandados nove meses, enquanto Barbosa et al. (1997), estudando o desenvolvimento do portaenxerto de pereira Taiwan Nashi-C, verificaram que foram necessários onze meses para atingirem o mesmo ponto, provavelmente o mesmo tempo que os marmelos do gênero Cydonia iriam levar para atingir o ponto de enxertia. Tais dados confirmam que o marmeleiro 'Japonês' apresenta crescimento vegetativo mais rápido que os demais genótipos com potencial para ser usado como porta-enxerto.

Portando, esse período de formação faz com que os portaenxertos estejam aptos para serem enxertados em época nãoideal da realização da enxertia para o marmeleiro (janeiro). Assim, estão sendo desenvolvidos experimentos no IAC visando a estudar a conservação de sementes do marmeleiro 'Japonês' a frio (temperatura baixa $/ 4^{\circ} \mathrm{C}$, reduzida $/-12^{\circ} \mathrm{C}$ e ultrabaixa temperatura $/-196^{\circ} \mathrm{C}$ - criopreservação, visando a adequar o cronograma da época de semeadura com a época ideal da realização da enxertia (julho), além de outros experimentos com épocas distintas de enxertia, tanto por borbulhia quanto por garfagem.

TABELA 1 - Porcentagem de emergência de plântulas de diferentes cultivares de marmeleiro. Jundiaí-SP, Centro APTA Frutas/IAC, 2006.

\begin{tabular}{|c|c|c|c|c|c|c|c|c|}
\hline \multirow[t]{2}{*}{ Cultivares } & \multicolumn{8}{|c|}{ Porcentagem de emergência* } \\
\hline & $1^{\circ}$ ava & liação - 30 dias & $2^{\circ}$ av & liação - 40 dias & $3^{\circ}$ ava & liação - 50 dias & $4^{\circ}$ aval & liação - 60 dias \\
\hline Japonês & 54,75 & $\mathrm{a}$ & 64,75 & $\mathrm{a}$ & 66,00 & $\mathrm{a}$ & 70,00 & $\mathrm{a}$ \\
\hline INTA-37 & 16,25 & $\mathrm{~b}$ & 18,75 & $\mathrm{~b}$ & 22,00 & $\mathrm{~b}$ & 22,00 & $\mathrm{~b}$ \\
\hline Provence & 13,25 & $\mathrm{~b}$ & 14,00 & $\mathrm{~b}$ & 14,75 & $\mathrm{c}$ & 14,75 & $\mathrm{c}$ \\
\hline Portugal & 17,66 & $\mathrm{~b}$ & 21,33 & $\mathrm{~b}$ & 23,00 & $\mathrm{~b}$ & 23,00 & $\mathrm{~b}$ \\
\hline $\mathrm{cv}(\%)$ & & 12,96 & & 12,76 & & 9,83 & & 7,93 \\
\hline
\end{tabular}

* Médias seguidas pela mesma letra na coluna não diferem entre si, pelo teste Tukey, ao nível de 5\% de probabilidade.

TABELA 2 - Altura média da parte aérea, número de folhas, massa seca média da parte aérea e da raiz de plântulas de diferentes cultivares de marmeleiro após 60 dias da semeadura. Jundiaí-SP, Centro APTA Frutas/IAC, 2006.

\begin{tabular}{|c|c|c|c|c|c|}
\hline \multirow[t]{2}{*}{ Cultivares } & \multicolumn{5}{|c|}{ Variáveis analisadas* } \\
\hline & $\begin{array}{l}\text { Altura. média P.A. } \\
(\mathrm{cm})\end{array}$ & & $\mathrm{N}^{\mathrm{o}}$ folhas & $\begin{array}{l}\text { Massa seca média } \\
\text { P.A. (mg) }\end{array}$ & $\begin{array}{l}\text { Massa seca média } \\
\text { raiz. (mg) }\end{array}$ \\
\hline Japonês & $5,90 \quad \mathrm{~b}$ & 5 & $\mathrm{~b}$ & $87,00 \quad b$ & $15,00 \quad \mathrm{a}$ \\
\hline INTA-37 & 7,72 a & 6 & a & 115,75 a & 18,50 a \\
\hline Provence & 7,19 a & 6 & $\mathrm{a}$ & $84,75 \quad b$ & $8,00 \quad b$ \\
\hline Portugal & $5,64 \quad b$ & 5 & $\mathrm{~b}$ & 48,33 & 9,66 \\
\hline cv (\%) & 6,13 & & 1,66 & 6,85 & 13,05 \\
\hline
\end{tabular}

* Médias seguidas pela mesma letra na coluna não diferem entre si, pelo teste Tukey, ao nível de 5\% de probabilidade.

TABELA 3 - Altura de plantas de diferentes cultivares de marmeleiro avaliado após o transplantio. Jundiaí-SP, Centro APTA Frutas/ IAC, 2006.

\begin{tabular}{|c|c|c|c|c|c|c|c|c|c|c|c|}
\hline \multirow[t]{2}{*}{ Cultivares } & \multicolumn{11}{|c|}{ Altura (cm)* } \\
\hline & 30 dias & \multicolumn{2}{|c|}{60 dias } & \multicolumn{2}{|c|}{90 dias } & \multicolumn{2}{|c|}{120 dias } & \multicolumn{2}{|c|}{150 dias } & \multicolumn{2}{|c|}{180 dias } \\
\hline Japonês & 8,45 a & 20,70 & $\mathrm{a}$ & 32,51 & $\mathrm{a}$ & 58,47 & $\mathrm{a}$ & 85,45 & $\mathrm{a}$ & 111,83 & $\mathrm{a}$ \\
\hline INTA -37 & $7,98 \mathrm{ab}$ & 11,82 & $\mathrm{~b}$ & 21,30 & $\mathrm{~b}$ & 40,72 & $\mathrm{~b}$ & 50,92 & $\mathrm{~b}$ & 68,26 & $\mathrm{~b}$ \\
\hline Provence & $6,88 \quad b$ & 10,00 & $\mathrm{~b}$ & 18,69 & $\mathrm{~b}$ & 34,04 & $\mathrm{~b}$ & 46,77 & $\mathrm{~b}$ & 63,96 & $\mathrm{~b}$ \\
\hline Portugal & $7,17 \mathrm{ab}$ & 9,69 & $\mathrm{~b}$ & 17,95 & $\mathrm{~b}$ & 36,04 & $\mathrm{~b}$ & 43,86 & $\mathrm{~b}$ & 68,13 & $\mathrm{~b}$ \\
\hline $\mathrm{cv}(\%)$ & 8,21 & & 19 & &, 69 & & 31 & & 83 & 6 & \\
\hline
\end{tabular}

* Médias seguidas pela mesma letra na coluna não diferem entre si, pelo teste Tukey, ao nível de 5\% de probabilidade. 
TABELA 4 - Diâmetro na altura de enxertia (15 cm acima do coleto) de plantas de diferentes cultivares de marmeleiro avaliado após o transplantio. Jundiaí-SP, Centro APTA Frutas/IAC, 2006.

\begin{tabular}{|c|c|c|c|c|c|c|c|c|c|c|c|c|}
\hline \multirow[t]{2}{*}{ Cultivares } & \multicolumn{12}{|c|}{ Diâmetro (cm)* } \\
\hline & \multicolumn{2}{|c|}{30 dias } & \multicolumn{2}{|c|}{60 dias } & \multicolumn{2}{|c|}{90 dias } & \multicolumn{2}{|c|}{120 dias } & \multicolumn{2}{|c|}{150 dias } & \multicolumn{2}{|c|}{180 dias } \\
\hline Japonês & 0,18 & $\mathrm{a}$ & 0,26 & $\mathrm{a}$ & 0,34 & $\mathrm{a}$ & 0,45 & $\mathrm{a}$ & 0,53 & $\mathrm{a}$ & 0,70 & $\mathrm{a}$ \\
\hline INTA-37 & 0,18 & $\mathrm{a}$ & 0,21 & $\mathrm{~b}$ & 0,25 & $\mathrm{~b}$ & 0,39 & $\mathrm{~b}$ & 0,42 & $\mathrm{~b}$ & 0,50 & $\mathrm{~b}$ \\
\hline Provence & 0,16 & $\mathrm{a}$ & 0,17 & $\mathrm{~b}$ & 0,28 & $\mathrm{~b}$ & 0,40 & $\mathrm{~b}$ & 0,45 & $\mathrm{~b}$ & 0,50 & $\mathrm{~b}$ \\
\hline Portugal & 0,15 & $\mathrm{a}$ & 0,18 & $\mathrm{~b}$ & 0,25 & b & 0,40 & $\mathrm{~b}$ & 0,40 & $\mathrm{~b}$ & 0,50 & $\mathrm{~b}$ \\
\hline cv (\%) & & 10,75 & & 9,52 & & 8,98 & & 4,02 & & 6,13 & &, 53 \\
\hline
\end{tabular}

* Médias seguidas pela mesma letra na coluna não diferem entre si, pelo teste Tukey, ao nível de 5\% de probabilidade.

\section{CONCLUSÃO}

O marmeleiro 'Japonês' apresenta maior porcentagem de emergência, maior altura e diâmetro e maior rapidez para as plantas atingirem o ponto de enxertia que os demais genótipos avaliados no presente trabalho.

\section{REFERÊNCIAS}

ABRAHÃO, E.; SOUZA, M.de; ALVARENGA, A.A. A cultura do marmeleiro em Minas Gerais. Belo Horizonte: EPAMIG, 1996. 23p. (Boletim Técnico, 47).

ABRAHÃO, E.; ALVARENGA, A.A.; SOUZA, M.de. Geminação das sementes do marmeleiro (Chaenomeles sinensis Koehne cv. Japonês). Revista Ciência e Prática, Lavras, v.19, n.3, p 342-343, 1995.

ABRAHÃO, E.; ALVARENGA, A.A.; SOUZA, M.de. A produção extrativa de um novo marmeleiro no Sul do Estado de Minas Gerais. Revista Ciência e Prática, Lavras, v.16, n.1, p.78, 1992.

ABRAHÃO, E.; ALVARENGA, A.A.; SOUZA, M.de. Marmeleiro (Chaenomeles sinensis) cv. Japonês - Porta-enxerto para marmeleiros, pereiras e nespereiras. Revista Brasileira de Fruticultura, Cruz das Almas, v.13, n.2, p.181-182, 1991.

BARBOSA, W.; CAMPO DALL'ORTO, F.A.; OJIMA, M.; NOVO, M.C.S.S.; BETTI, J.A.; MARTINS, F.P. Conservação e germinação de sementes e desenvolvimento de plântulas da pereira porta-enxerto Taiwan Nashi-C. Scientia Agrícola, Piracicaba, v.54, n.3, p.147-151, 1997.

CAMPODALL'ORTO, F.A.; OJIMA, M.; FERRAZ, E.S.B.; IGUE, T.; MARTINS, F.P.; RIGITANO, O. Germinação das sementes de marmelo: meios e períodos de estratificação e processos de preparo. Bragantia, Campinas, v.46, n.2, p.315-328, 1987.

CAMPO DALL'ORTO, F.A. Marmeleiro (Cydonia oblonga Mill.): propagação seminífera, citogenética e radiossensitividade - bases ao melhoramento genético e a obtenção de porta-enxertos. 1982. 161f. Dissertação (Mestrado em Agronomia) - Universidade de São Paulo, Escola Superior de Agricultura “Luiz de Queiroz”, Piracicaba.

FERREIRA, D.F. Análise estatística por meio do SISVAR (Sistema para Análise de Variância) para Windows versão 4.0. In: REUNIÃO ANUAL DA REGIÃO BRASILEIRA DA SOCIEDADE INTERNACIONAL DEBIOMETRIA, 45., 2000, São Carlos. Anais... São Carlos: UFSCar, 2000. p.255-258.
GOMES, F.P. Curso de estatística experimental. 14. ed. Piracicaba: USP/ESALQ, 2000. 477p.

PIO, R.; CAMPO DALL'ORTO, F.A.; ALVARENGA, A.A.; ABRAHÃO, E.; BUENO, S.C.S.; MAIA, M.L. A Cultura do marmeleiro. Piracicaba: ESALQ/USP, 2005a. 53p. (Série Produtor Rural, 29).

PIO, R.; RAMOS, J.D.; CHALFUN, N.N.J.; GONTIJO, T.C.A.; CARRIJO, E.P.; MENDONÇA, V.; ALVARENGA, A.A.; ABRAHÃO, E. Enraizamento de estaca dos marmeleiros 'Portugal' e 'Japonês' em diferentes ambientes e posições no recipiente. Revista Ciência e Agrotecnologia, Lavras, v.29, n.5, p.968-973, 2005b.

PIO, R.; ARAÚJO, J.P.C.de; SCARPARE FILHO, J.A.; MOURÃO FILHO, F.de A.A.; ALVARENGA, A.A.; ABRAHÃO, E. Potencial de propagação de cultivares de marmeleiro por estaquia. Revista Brasileira de Fruticultura, Jaboticabal, v.26, n.2, p.287-289, 2004a.

PIO, R.; RAMOS, J.D.; CHALFUN, N.N.J.; GONTIJO, T.C.A.; CARRIJO, E.P.; TOMASETTO, F.; VISIOLI, E.L.; BETTIOL NETO, J.E. Enraizamento de estacas lenhosas dos marmeleiros 'Portugal' e 'Japonês' tratadas com ácido indolbutírico. Revista Ceres, Viçosa, v.51, n.298, p.777-786, $2004 b$. 